\title{
The "Let's Get Alarmed!" initiative: a smoke alarm giveaway programme
}

Carolyn DiGuiseppi, Suzanne Slater, Ian Roberts, Lucy Adams, Mark Sculpher, Angela Wade, Mark McCarthy

\begin{abstract}
Objectives-To reduce fires and fire related injuries by increasing the prevalence of functioning smoke alarms in high risk households.

Setting-The programme was delivered in an inner London area with above average material deprivation and below average smoke alarm ownership. The target population included low income and rental households and households with elderly persons or young children.

Methods-Forty wards, averaging 4000 households each, were randomised to intervention or control status. Free smoke alarms and fire safety information were distributed in intervention wards by community groups and workers as part of routine activities and by paid workers who visited target neighbourhoods. Recipients provided data on household age distribution and housing tenure. Programme costs were documented from a societal perspective. Data are being collected on smoke alarm ownership and function, and on fires and related injuries and their costs.
\end{abstract}

Results-Community and paid workers distributed 20050 smoke alarms, potentially sufficient to increase smoke alarm ownership by $50 \%$ in intervention wards. Compared with the total study population, recipients included greater proportions of low income and rental households and households including children under 5 years or adults aged 65 and older. Total programme costs were $£ 145087$.

Conclusions - It is possible to implement a large scale smoke alarm giveaway programme targeted to high risk households in a densely populated, multicultural, materially deprived community. The programme's effects on the prevalence of installed and functioning alarms and the incidence of fires and fire related injuries, and its cost effectiveness, are being evaluated as a randomised controlled trial.

(Injury Prevention 1999;5:177-182)

Keywords: smoke alarms; residential fire injuries; home

$\begin{array}{ll}\text { Economics, University } & \text { Keyword } \\ \text { of York } & \text { safety }\end{array}$

M Sculpher

Correspondence to: Dr C DiGuiseppi, Senior Research Fellow, Department of Epidemiology, Institute of Child Health, 30 Guilford Street, London WC1N 1EH, UK.
Dwelling fires caused 553 deaths and 13064 non-fatal casualties in England and Wales in 1996, accounting for nearly $75 \%$ of all fire fatalities and casualties. ${ }^{1}$ Among children aged $0-14$ in England and Wales, fires are the second leading cause of unintentional injury death. ${ }^{2}$ There is a steep social class gradient in the risk of fire related death, ${ }^{3}$ due in part to social class differences in the prevalence of risk factors for residential fires such as lone parenthood, financial difficulties, and living in rental accommodation or housing in poor condition. $^{4}$

Differences in smoke alarm ownership might also help explain this social class gradient: households least likely to have alarms include lone parent and low income households, and rental accommodation. ${ }^{5}$ Fires detected by alarms are associated with a reduced risk of death, injury, and property damage, ${ }^{1}$ and smoke alarm ownership is associated with a reduced risk of fire death. ${ }^{6} 7$

Trials of community injury prevention education that included smoke alarm promotion found little or no effect on either alarm ownership or burn incidence. ${ }^{8-10}$ In contrast, community smoke alarm giveaway programmes have reported significant increases in alarm ownership and reductions in fire related injuries. ${ }^{11} 12$ Four years after distribution of 10100 free alarms in Oklahoma City, serious residential fire related injuries had declined $80 \%$ in the target area, compared with a small increase elsewhere in the city. ${ }^{11}$ In Philadelphia, the prevalence of functioning smoke alarms was $19 \%$ higher in intervention areas, where inspectors visited intervention households and installed free alarms, than in control areas. ${ }^{12}$ Fire related injuries declined more in intervention areas than in control areas, although these results were not statistically significant (written communication, D Schwarz, 17 July 1998). Both programmes were evaluated as non-randomised controlled trials, hence results may have been biased by systematic differences between study groups. In addition, the generalisability of these programmes to the multicultural, ethnically diverse, densely housed population of inner London is not established.

In the two inner London boroughs of Camden and Islington fires are a leading cause of unintentional injury death, ${ }^{13}$ but only $47 \%$ of households own smoke alarms ${ }^{14}$ compared with a national prevalence (in 1995) of $72 \% .^{5}$ We undertook a randomised controlled trial to evaluate the effect of a community-wide smoke alarm giveaway programme on smoke alarm ownership, fires, and fire related injuries in these two boroughs. In this paper we describe the development and implementation of the giveaway programme. 
Methods

POPULATION

Camden and Islington are two of 33 London boroughs, with a combined population of about 350 000. The boroughs are divided into 46 political wards comprising, on average, 4000 households each. The average Jarman underprivileged area (UPA) scores ${ }^{15}$ for the two boroughs are 40.4 and 33.9, respectively, indicating substantial material deprivation.

\section{STUDY DESIGN}

The study is a cluster randomised controlled trial, randomised by ward. We included all 20 wards in each borough that had above average material deprivation (Jarman UPA scores $\geqslant 20$ ). These 40 wards were pair matched by Jarman score. Using computer generated random numbers, an independent statistician randomly allocated wards within these matched pairs to intervention or control group.

The trial was approved by the Great Ormond Street Hospital for Sick Children NHS Trust/Institute of Child Health Research Ethics Committee.

PROGRAMME DEVELOPMENT

Objective

To increase smoke alarm ownership in intervention wards from $47 \%$ to the national prevalence of $72 \%$ required the distribution of 20000 smoke alarms. Target high risk households included rental accommodation, low income households (using occupancy of council (local government owned) housing as a proxy), elderly people, and families with young children.

\section{Development}

The lead agencies were the Camden and Islington Accident Prevention Alliances, which are multisectoral working groups comprising local government; health visitors, home care, and health promotion services; hospitals; primary care teams; district nurses; police; universities; and voluntary agencies. The alliances were established by the local health authority in 1995. One of their objectives was the development of collaborative accident prevention programmes. To support the alliances, the Camden and Islington Health Authority funded two project staff to develop programmes and create local community partnerships to deliver them, and funded investigators at the Institute of Child Health to provide research support.

The alliances, with input from project and research staff, identified fire related injuries as a priority for intervention. Between mid-1996 and early 1997 the project and research staff, with substantial input from health authority staff and the two alliance Chairs, developed the programme and its evaluation and secured financial and institutional support.

Funding, resources, and facilitators

The Home Office (Ministry of the Interior) provided ministerial endorsement, advice, and 25000 free fire safety brochures. The Home Office Fire Safety Unit also hosted an explora- tory meeting in mid-1996, attended by representatives from the London Fire Brigade and a smoke alarm manufacturer, the alliance Chairs, and research and project staff. The Fire Brigade subsequently agreed to provide training and data access, the manufacturer offered alarms at cost (later matched by a second manufacturer) and one alliance Chairman, a senior council officer with budgetary powers, staff, and resources, offered $£ 5000$ and in-kind contributions including vans and drivers to transport alarms, alarm storage, and installation. His commitment evoked similar support from the other council. In-kind contributions were also provided by the health authority (storage, supplies, photocopying) and local grocers (packaging). The financial and institutional commitment from both local councils and the local health authority facilitated further fundraising efforts.

The research team successfully applied to the Medical Research Council (MRC) to fund a trial to evaluate the programme. The MRC's endorsement was instrumental in the research team's securing funds from the Home Office and the British Medical Association (whose headquarters are in Camden). Reducing inequalities in health was a major plank of the new (Labour) government's health policy, so after the change in government in May 1997 we reapplied to the Department of Health for funding. This request, previously denied, was successful.

PROGRAMME IMPLEMENTATION

Smoke alarm giveaway

The programme provided free smoke alarms, batteries and fittings, and informational brochures on smoke alarms, fire safety and prevention, packed in transparent bags by project staff, volunteers, and paid workers. An indemnification/consent form that included questions on housing tenure and composition was developed for alarm recipients, but those who refused to complete or sign the form were not denied an alarm. Contact information for the principal project coordinator was provided to recipients in case of questions or concerns.

Brochures were available for householders who already owned or who refused an alarm. We endeavoured to identify distribution points so that if occupants were out when visited, notices could be left about collection places, dates, and times. To increase uptake, flyers and posters about the programme were provided in advance in some areas.

\section{Distribution}

We initially contemplated using the Oklahoma City model, in which groups of volunteers, accompanied by a slowly driven fire engine with flashing lights, siren, and banners, walked through residential neighbourhoods using a loudspeaker to inform residents of the giveaway. ${ }^{11}$ Residents who came out into the streets in response received a free alarm. The high rise apartment buildings, heavy traffic, narrow streets, and complex street layout in inner London precluded this model, however. Project staff were also unsuccessful 
in recruiting volunteers, attempted through borough volunteer centres and other voluntary sector organisations, advertisements, flyers, and newsletters. The volunteer centres questioned the volunteers' safety in high risk neighbourhoods and the willingness of residents to open doors to volunteers not known to them. Therefore, we decided to deliver the programme through groups and workers active in the community.

Community group recruitment began in February 1997. Project staff audited each intervention ward to identify public, voluntary, community, and private sector organisations that might assist the distribution, wrote and telephoned each organisation (a total of 120), and visited organisations expressing interest.

Community workers including district nurses, health visitors, home care workers, meals-on-wheels services, voluntary sector workers, sheltered housing wardens, caretakers and managers of council properties, and special interest (for example, minority ethnic) group workers were asked to distribute alarms during routinely scheduled home visits or as part of their routine activities. Representatives of tenants' and residents' associations and housing cooperatives agreed to visit client households to offer alarms, or to inform these households of the availability of alarms at representatives' homes or tenants' halls (meeting rooms located within apartment blocks). Local sites likely to be visited by target householders, including health, child care and community centres, and neighbourhood rent payment offices, were asked to offer alarms during their regular hours. Officers from one council agreed to distribute alarms to privately rented multiple occupancy households that had been found to lack alarms in a recent survey. A few teams of volunteers, primarily recruited from the councils, health authority, and University College London, distributed alarms door-to-door.

After four months, alarm distribution rates by community groups were insufficient to meet programme objectives. To complete the distribution, we hired hourly workers through contracts with the two councils, which maintain rosters of temporary employees for similar work (for example, census taking) and which screened the workers, provided identification cards, and administered their payroll. Project staff trained and supervised the workers, who visited target households, initially in pairs and later alone, covering neighbourhoods in teams of five to 10 people.

\section{Training}

The London Fire Brigade trained project staff about fire safety and the function, maintenance, and installation of alarms. These staff in turn briefly trained distributors about fire safety and smoke alarms, and the distribution process. Each distributor received scripts and question-and-answer sheets covering likely scenarios and problems.
Installation

The two councils agreed to install alarms when recipients requested installation on the indemnification form.

\section{Alarm maintenance}

One year after the programme, postcards were sent to all recipients who completed indemnification forms, reminding them to test and vacuum alarms and to change batteries.

\section{Project coordination}

Between February and October 1997, two staff working two thirds time and one working half time on the project, recruited, trained, and coordinated community groups and volunteers to distribute alarms; produced distribution tools (informational flyers, posters, contracts, etc); organised alarm storage, packaging, delivery, and installation; and performed troubleshooting, administrative, and other tasks. From November 1997 to January 1998 two project staff, working two thirds time on the project, recruited, trained, and coordinated hourly employees to distribute alarms, and continued to perform organisational and administrative tasks.

\section{PROGRAMME EVALUATION}

We documented the number and types of community groups recruited, and the number of alarms distributed by each group. Estimates of hours worked by paid distributors were based on invoices received. Paid distributors collected data on the numbers of households visited, occupants at home, and occupants who owned, accepted, or refused alarms. These data were extrapolated to the households visited by community workers, for which no data were available. It is likely, however, that a substantially greater proportion of those scheduled to receive visits from, for example, home care workers, were at home when visited compared with households visited without appointments.

We gathered data on the total number of alarms collected from distribution sites. These data did not differentiate between recipients who came to collect alarms after receiving informational flyers and those who collected them during visits made for other reasons (for example, for health or child care). We did not have data on the total number of households that received flyers or the number of persons who visited distribution sites as part of their routine activities.

The indemnification/consent form included questions on housing tenure and household composition by age. We obtained 1991 census data on housing tenure and household composition for the two boroughs as a whole (written communications, Islington and Camden councils, September 1996).

We documented the costs of the programme from a societal perspective - that is, costs to all agencies and individuals, including valuation of in-kind contributions. We based the value of voluntary workers' time spent distributing alarms on the cost per alarm distributed by paid workers. We did not include the costs of the evaluation or fundraising by the research 


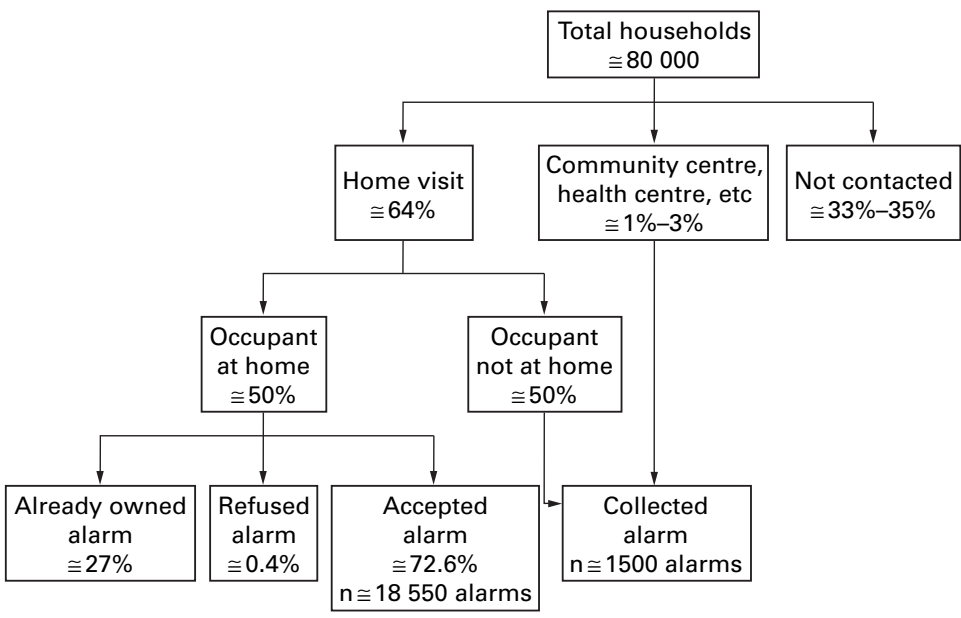

Figure 1 Proportions and numbers of distributed smoke alarms according to method of distribution.

Table 1 Proportions of alarm recipients and of Camden and Islington residents as a whole, by housing tenure and household composition

\begin{tabular}{llll}
\hline Characteristics & Alarm recipients * (\%) & $\begin{array}{l}\text { Camden:† 1991 } \\
\text { census (\%) }\end{array}$ & $\begin{array}{l}\text { Islington: 1991 } \\
\text { census (\%) }\end{array}$ \\
\hline Rent accommodation & $80(10922 / 13633)$ & 66 & 73 \\
$\quad$ Rent from council & $67(8853 / 13264)$ & 34 & 48 \\
$\quad$ Rent from housing association & $6(809 / 13264)$ & 9 & 11 \\
$\quad$ Rent from private landlord & $7(891 / 13264)$ & 23 & 15 \\
Any occupants aged <5 & $17(2306 / 13317)$ & 6 & 7 \\
Any occupants aged $\geqslant 65 \ddagger$ & $28(3724 / 13445)$ & 16 & 27 \\
\hline
\end{tabular}

${ }^{\star}$ Denominators comprise the total number of respondents to each relevant question on the indemnification form.

†Data from 1991 censuses were provided by Camden and Islington councils from Office for National Statistics data (written communications, September 1996, December 1998). Proportions for Camden include the six wards excluded from the trial.

$\ddagger$ Proportions for Camden and Islington include men aged $\geqslant 65$ and women aged $\geqslant 60$.

team in these estimates, as these were not part of the giveaway programme.

Research assistants blinded to ward intervention status are collecting data on smoke alarm ownership, installation and function, fire safety and prevention knowledge, and on fire related injuries, and reported fires and their costs. Methodological details of data collection will be reported later, with the results of the randomised controlled trial evaluating the programme. The evaluation will include a cost effectiveness analysis of the giveaway programme in terms of the net costs incurred to prevent fires and fire related injuries.

\section{Results}

GIVEAWAY PROGRAMME

A total of 108 community organisations participated in the programme, most of which were tenants' and residents' associations, housing cooperatives, and specialist community groups. Between July and October 1997 community groups and workers distributed 6250 alarms, $73 \%$ of which were distributed by the tenants' and residents' associations. Between November 1997 and January 1998 paid hourly employees worked approximately 2000 person-hours to distribute 13800 alarms door-to-door. We distributed 20050 free smoke alarms.

We visited or otherwise contacted an estimated two thirds of the 80000 households in intervention wards, including nearly all council estates. Most alarms were provided at home visits (fig 1). (The total for home visits includes alarms collected from the homes of residents' and tenants' association representatives, and from tenants' halls, estimated to be at most $10 \%$ of this total.) Fewer than $10 \%$ of the alarms were collected from the various distribution sites in the community (fig 1). Approximately $8 \%$ of households requested installation by the relevant councils.

We obtained signed indemnification forms from 14496 subjects, of whom 14039 (97\%) resided in intervention wards, 449 (3\%) in control wards, and eight $(<1 \%)$ outside the study wards. Among recipients residing in intervention wards $50 \%$ were from Camden and $50 \%$ from Islington. The distributions of housing tenure and household age distribution among intervention ward recipients who responded to these questions on the indemnification forms, and among residents of Islington and Camden as a whole, are shown in table 1.

The giveaway programme cost $£ 145087$, of which more than $60 \%$ was for personnel costs (table 2). The one year reminder postcards cost $£ 12736$, most of which paid for data entry.

BARRIERS TO THE PROGRAMME

We initially approached about 120 community groups and organisations to participate in the programme, of whom 108 (90\%) eventually

Table 2 Costs of the smoke alarm giveaway programme

\begin{tabular}{|c|c|c|}
\hline Item & Resources & Value \\
\hline Smoke alarm packs & 20050 alarms, batteries, fittings, manufacturer's instructions & $£ 49200$ \\
\hline $\begin{array}{l}\text { Educational brochures on fire } \\
\text { safety and smoke alarms }\end{array}$ & $\begin{array}{l}\text { (1) } 25750 \text { fire safety brochures (in English and other languages); (2) } 25000 \text { smoke } \\
\text { alarm brochures }\end{array}$ & $£ 1392$ \\
\hline${\text { Bags } \star^{\star}}^{2}$ & 25000 bags & $£ 125$ \\
\hline Supplies $\star$ & 25 clipboards & 45 \\
\hline Photocopying $\star$ & 50000 units (indemnity forms, address sheets, leaflets, posters, contacts, drop cards) & $£ 2225$ \\
\hline Transport ${ }^{\star}$ & Vans and drivers for 50 days@f125/day & 6250 \\
\hline Storage ${ }^{\star}$ & $\approx 5-6$ boxes $(20$ alarms/box $)$ per day $\times 6$ months & $£ 200$ \\
\hline Training $\star$ & London Fire Brigade staff: 3 person hours plus travel costs & $£ 217$ \\
\hline Baggingt & 468 person hours & 1638 \\
\hline Distribution $\dagger$ & 4831 person hours & $\AA_{23915}$ \\
\hline Installation $\dagger$ & 1604 alarms installed & $£ 12000$ \\
\hline Programme coordination $\dagger$ & 2 staff at $2 / 3$ FTE $\times 12$ months; 1 staff at $0.5 \mathrm{FTE} \times 7$ months & $£ 47791$ \\
\hline Pilot test ${ }^{\star}$ & 18 person hours & $£ 89$ \\
\hline Giveaway programme & Subtotal & $£ 145087$ \\
\hline Mailing list preparation & Entry of 14496 names and addresses into computerised database & $£ 9228$ \\
\hline Reminder postcards & 14039 cards, printing, postage, and mail sorting & $£ 3508$ \\
\hline \multirow[t]{2}{*}{ Reminder postcards } & Subtotal & $£ 12736$ \\
\hline & Grand total & $£ 157823$ \\
\hline
\end{tabular}

*In-kind contributions and donations.

†In-kind contributions, in part. FTE = full time equivalent. 
agreed. One barrier to participation was mistrust of local government initiatives based on previous experiences. Project staff committed substantial effort and repeated visits to persuade them to become involved. This persuasion was aided by the involvement of the Great Ormond Street Hospital for Children, which has a positive image as a well respected charitable organisation.

A second barrier was the programme's organisation as a trial. Several community groups with clients in both control and intervention wards refused to participate since some clients would not receive alarms. One of these agreed to provide their client list, but not to distribute alarms.

A barrier to continuing participation was the time and effort required to distribute alarms. Hence, in addition to advice, project staff also provided direct assistance to groups whenever requested (for example, distributing flyers, manning distribution booths).

As predicted by the volunteer centres, community mistrust of strangers at the door (as well as of the local government) led to some difficulties with distribution by paid workers. For example, several residents called police or project staff when confronted with council identification badges, on the assumption that the local government was unlikely to give anything away! A rapid explanation at the door, or mention of Great Ormond Street Hospital, was usually sufficient to overcome this barrier.

\section{Discussion}

The Let's Get Alarmed! initiative distributed 20050 smoke alarms to households in materially deprived wards in Camden and Islington, and successfully targeted low income households, households including young children and elderly adults, and households renting their accommodation. We do not yet have data on how many alarms were installed and are functioning. Recipients of free alarms may be less likely to install the alarms than are those who shop for and purchase an alarm. In Oklahoma City, the prevalence of installed and functioning smoke alarms among recipients 12 months after the giveaway programme was only $51 \% .{ }^{11}$ Given our target population, we speculate that a substantial proportion of the alarms may not have been installed. Given that $97 \%$ of the 20050 alarms were distributed in intervention wards, if half the distributed alarms were actually installed (including those installed by the councils), the prevalence of installed smoke alarms among the 80000 households in intervention wards one year after the programme would have increased from $47 \%{ }^{14}$ to about $59 \%$.

An early plan by the alliances to conduct a community education campaign was discarded after a systematic review of previously conducted trials ${ }^{8-10} 16$ provided little support for broad based community injury prevention education as an effective tool to prevent fire related injuries. The investigators for Project Burn Prevention suggested that the effect of their programme may have been attenuated because only a small proportion of the target population is exposed to the educational messages, understands the messages, and subsequently changes and maintains safety practices so as to reduce the risk of injury. ${ }^{16}$ The investigators also speculated that their programme addressed too many topics (that is, preventing all types of burns) for effective learning to occur. ${ }^{16}$

Our programme, like previous smoke alarm giveaway programmes, ${ }^{11}{ }^{12}$ focused only on smoke alarms and offered the alarm itself, rather than advice about it; the potential barriers of attenuation and multiplicity of messages were thus avoided. High cost and limited access to recommended protective devices are also important barriers to implementing safety advice, ${ }^{17}$ particularly for low income families, who are also least likely to own smoke alarms. ${ }^{5}$ We addressed the barriers of cost and access by delivering free alarms at the home or other convenient sites.

The social, ethnic, and cultural environment, the complex (and narrow) street layout, and the housing density, type, and tenure found in inner London made it untenable to adopt the successful Oklahoma city model, ${ }^{11}$ and resources and staffing were insufficient to duplicate the programme used in Philadelphia. ${ }^{12}$ Hence, a new model was developed, which initially involved the recruitment of community groups, and subsequently paid hourly employees, to distribute alarms.

Because project staff required less time to coordinate and supervise paid workers than to assist and coordinate the community groups, it might have been more cost effective to use only paid workers despite their high direct cost. It is not possible to say whether the entire programme could have been implemented using paid workers, however, because extensive involvement of community groups had already been accomplished before the paid workers were hired. Such involvement might have raised awareness and acceptance within the community, making distribution by paid workers more efficient.

Because the intervention was organised as part of a trial and we wished to limit requests for alarms from control wards, we did not publicise the programme. Therefore, time was spent at the door explaining the programme and overcoming mistrust of the occupants. Whether informational flyers distributed in advance improved uptake is unknown. Widespread publicity about the programme might have increased awareness and hence acceptance.

This programme experienced most of the barriers to community involvement that have previously been identified. ${ }^{18}$ Involving community groups with the programme also led to important benefits, however, including the development of new community networks and contacts that will be useful for future alliance activities. The community organisations were pleased with their raised profile among constituents. In addition, by visiting households to distribute alarms, they recognised constituents requiring assistance and encouraged others to 
become involved in their organisations. Most felt that programme participation facilitated their regular activities.

\section{Conclusions}

A community giveaway programme was successful in distributing 20050 alarms to high risk households. The programme required a substantial investment of resources. The effectiveness of the programme in reducing fire related injuries is currently being assessed. For those contemplating such a programme, we recommend laying the groundwork in advance, clarifying roles and obtaining written commitments from participants to avoid misunderstandings, publicising the programme, and ensuring adequate staff and resources are available in advance. Until such programmes have been shown to be effective, they should be performed within the context of a controlled evaluation.

We gratefully acknowledge the Camden and Islington Accident Prevention Alliances, London Boroughs of Camden and Islington, Camden and Islington Health Authority, Home Office, Department of Health, British Medical Association, Dicon Safety Products (UK) Ltd, BRK Brands Europe Ltd, Great Ormond Street Hospital Children's Fund, London Fire Brigade, J Sainsbury Ltd, and Waitrose Ltd. We would also like to acknowledge Lia Fernald, Charles Monkham, Sarah Pratap, David Taylor, and Vicki Taylor, for their efforts on behalf of the programme.

1 Collier P, Watson L. Summary fire statistics: United Kingdom 1996. London: Government Statistical Service, 1998.

2 DiGuiseppi C, Roberts I. Injury mortality among children and teenagers in England and Wales, 1992. Inj Prev 1997; 3:47-9.
3 Roberts I, Power C. Does the decline in child injury mortality vary by social class? A comparison of class
specific mortality in 1981 and 1991 . BMF 1996;313:784-6. specific mortality in 1981 and 1991. BMF 1996;313:784-6.
4 Budd T, Mayhew P. Fires in the home in 1995: results from the British Crime Survey. London: Government Statistical Service, 1997.

5 Roberts I. Smoke alarm use: prevalence and household predictors. Inj Prev 1996;2:263-5.

6 Runyan CW, Bangdiwala SI, Linzer MA, et al. Risk factors for fatal residential fires. N Engl f Med 1992;327:859-63.

7 DiGuiseppi C, Roberts I, Li L. Smoke alarm ownership and house fire death rates in children. $f$ Epidemiol Community Health 1998;52:760-1.

8 Guyer B, Gallagher SS, Chang B-H, et al. Prevention of childhood injuries: evaluation of the Statewide Childhood Injury Prevention Program (SCIPP). Am f Public Health 1989;79:1521-7.

9 Ozanne-Smith J, Sherrard J, Brumen IA, et al. Communitybased injury prevention evaluation report: Shire of Bulla Safe Living Program. Monash University Accident Research Centre, Report No 66, December 1994.

10 MacKay AM, Rothman KJ. The incidence and severity of burn injuries following Project Burn Prevention. Am f Public Health 1982;72:248-52.

11 Mallonee S, Istre GR, Rosenberg M, et al. Surveillance and prevention of residential-fire injuries. $N$ Engl $f \mathrm{Med}$ 1996;335:27-31.

12 Schwarz DF, Grisso JA, Miles C, et al. An injury prevention program in an urban African-American community. $A m \mathcal{F}$ Public Health 1993;83:675-80.

13 DiGuiseppi C, Allen D. Injury deaths in Camden and Islington residents. London: Institute of Child Health, 1997.

14 Adams L, DiGuiseppi C. A population based survey to estimate the prevalence of ownership and maintenance of smoke alarms in households in two inner London boroughs. International fournal of Health Promotion and Education 1999;37:65-7.

5 Jarman B. Underprivileged areas: validation and distribution of scores. BMF 1984;289:1587-92.

16 McLoughlin E, Vince CJ, Lee AM, Crawford JD. Project Burn Prevention: outcome and implications. Am f Public Health 1982;72:241-7.

17 Paul CL, Redman S, Evans D. The cost and availability of devices for preventing childhood injuries. $\mathcal{F}$ Paediatr Child Health 1992;28:22-6.

18 Department of Health. In the public interest: developing a strategy for public participation in the National Health Service. London: Department of Health, 1998.

\section{Editorial Board Member: brief biography}

\section{LOIS A FINGERHUT}

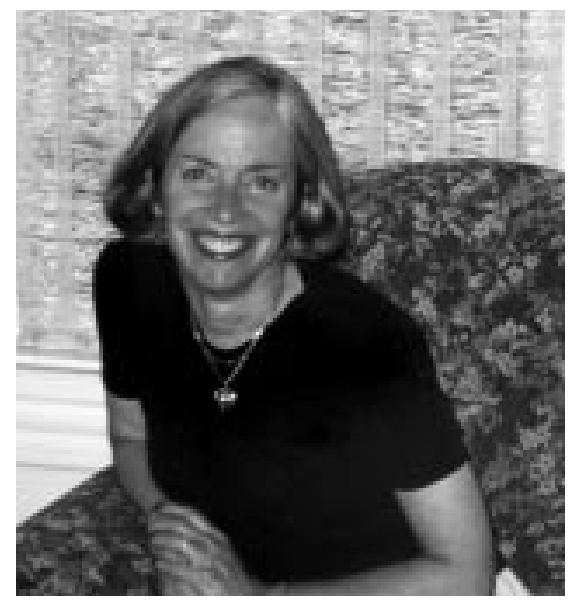

Lois A Fingerhut is the chair of the International Collaborative Effort (ICE) on injury statistics and is the special assistant for injury epidemiology in the Office of Analysis, Epidemiology, and Health Promotion at the National Center for health Statistics, CDC, where she has been working since 1977 .

She is also a co-chair of the Data Committee of the Injury Control and Emergency Health Services section of the American Public Health Association.

She received a master's degree in demography in 1975 from Georgetown University. Her injury research generally includes analyses of national mortality and morbidity databases. 